\title{
Research
}

\section{Supine Mini- Percutaneous Nephrolithotripsy (Mini PCNL) for Renal Stones 0.5 - 2 CM in Pediatric Age Group: New Experience of TBRI}

\author{
Khaled Eleseily, Hani Nour*, Mohamed Badawy, Mohamed Ali \\ Urology Department, Theodor Bilharz Research Institute, Giza, Egypt
}

^Correspondence to: Hani NOUR; Urology Department, Theodor Bilharz Research Institute Giza, Egypt; E-mail: hani_nour@hotmail.com

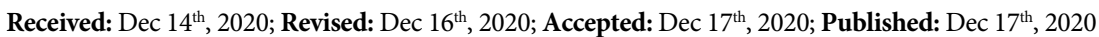

Citation: Eleseily K, Nour H, Badawy M, Ali M. Supine mini- percutaneous nephrolithotripsy (mini PCNL) for renal stones 0.5 - $2 \mathrm{~cm}$ in pediatric age group: New experience of TBRI. Urology Open A Open J. 2020; I(2): 39-42. doi: 10.33169/uro.UOAOJ-I-110

\begin{abstract}
Objective

To establish the new experience as well as to evaluate the safety and efficacy of mini percutaneous nephrolithotripsy (mini PCNL) in treatment of kidney stones $0.5-2 \mathrm{~cm}$ in pediatric age group.
\end{abstract}

\section{Patients and Methods}

Between December 2018 and October 2020 seventeen patients admitted to the Urology Department, presented with renal pelvis or calyceal stone $(5-20 \mathrm{~mm})$ were enlisted for mini PCNL. Achieving success of the technique is considered when stone free or radiologically insignificant residual fragments $<4 \mathrm{~mm}$.

\section{Results}

The demographic data in this study is comparable with those in adults age group regarding the stone size with no statistical significance. Meanwhile, the operative time was $59.71 \pm 19.44 \mathrm{~min}$, and Fluoroscopy times had mean of $8.11 \pm 2.05 \mathrm{~min}$. The stone free rate was $96.2 \%$ in mini PCNL, one case of mini PCNL (5.9\%) had significant bleeding and needed transfusion. One patient of mini PCNL (5.9\%) had perforation in the renal pelvis which was resolved with insertion of Double J stent \& nephrostomy.

\section{Conclusion}

Supine mini PCNL can be an effective and alternative option for treatment of renal stones $0.5-2 \mathrm{~cm}$ in pediatric age group. Supine mini PCNL has accepted operative and postoperative course. Larger numbers of patients will be more effective to confirm these results.

Keywords: Pediatric; Mini percutaneous nephrolithotomy; Stone.

\section{INTRODUCTION}

The renal stone has upgrading role in the morbidity and quality of life of patients and its prevalence is estimated to be about $10 \% .{ }^{1}$ Also, the recurrence of renal stones may be up to $50 \%{ }^{2}$ The impact of recent technology on the kidney stone management has a great role especially the advancement of minimally invasive technique as Extracorporeal Shock Wave Lithotripsy (ESWL), Percutaneous Nephrolithotomy (PCNL), Retrograde Intra Renal Surgery (RIRS). ${ }^{3}$ Percutaneous Nephrolithotomy
(PCNL) has stand the test of time as an effective treatment for renal lithiasis, it is associated with high success rates, decreased morbidity, and fewer complications in relation to conventional renal stone surgeries. In ESWL ; the size, shape, and component of renal stones affect the stone free rate in comparison to PCNL which still has a great role, ${ }^{3}$ and it has the upper hand in the treatment of large pelvic stone $(15-20 \mathrm{~mm}$ or more), and in lower calyx stone less than $20 \mathrm{~mm}$ with unfavorable conditions for ESWL as recommended by guidelines of European association of urology. ${ }^{4}$ 
PCNL is also indicated when there is failure of ESWL, staghorn stones, and also in patients with hard stones (eg. Calcium monohydrate). PCNL morbidities are associated with the tract size..$^{5-7}$ Mini PCNL is begun when the technological advancement allows using instruments for a tract less than $20 \mathrm{Fr}$ to extract renal stones which offers the same stone free rate in comparable with PCNL. ${ }^{7-14}$ This work aims to evaluate the safety and efficacy of mini percutaneous nephrolithotripsy (mini PCNL) in treatment of kidney stones in children (15mm-20mm) in its longest diameter.

\section{PATIENTS AND METHODS}

Seventeen children presented to urology department, Theodor bilharz Research Institute, Giza, Egypt with either calyceal and/or pelvic kidney stone $(0.5-20 \mathrm{~mm})$ in the period between December 2019 and October 2020. Patient assessment required thorough full medical history, general, local examination, laboratory investigation (urinalysis, complete blood count, kidney function test, liver function test, and random blood glucose level), and radiological investigation in the form of computed tomography (CT). CT scan calculates the size of the stone in its longest diameter.

Parents and children patients were counseled and informed about the advantages, disadvantages, and possible complications of $\mathrm{m}$ PCNL . All parents received written informed consent before the surgery to be signed. Patients with history of kidney stones surgery or congenital anomalies were excluded from the study. Complete blood count, serum biochemistry, combined $\mathrm{X}$ ray of the urinay tract (XR KUB) and renal ultra sound were done to evaluate residual stone at the first postoperative day. The success of the technique is considered when status is stone-free or clinically insignificant residual fragments $<4 \mathrm{~mm}$. All demographic data are presented in [Table 1].

Table 1. Demographic data.

\begin{tabular}{|l|l|}
\hline Age (Median/Range) & $5.6 \pm 6.91$ \\
\hline Sex (M/F-N/\%) & $12 / 70 \%-5 / 30 \%$ \\
\hline BMI (Mean \pm SD) & $15.76 \pm 9.34$ \\
\hline Size (mm- Mean \pm SD) & $17.43 \pm 5.2$ \\
\hline Number (Median/Range) & $1(1-2)$ \\
\hline Density (Hounsfield Unit- Mean \pm SD) & $730( \pm 236)$ \\
\hline Site & \\
\hline Pelvis (n/\%) & $9(55.1 \%)$ \\
\hline Lower calyx (n/\%) & $14(82.6 \%)$ \\
\hline Pelvi-calyceal (lower) (n/\%) & $2(11.8 \%)$ \\
\hline Laterality & \\
\hline Right $($ n/\%) & $12(70 \%)$ \\
\hline Left $(n / \%)$ & $5(30 \%)$ \\
\hline
\end{tabular}

\section{Operative Technique}

All patients received a prophylactic antibiotic before beginning of the procedure. The patient was in lithotomy position and a $4 \mathrm{~F}$ retrograde ureteric catheter was placed in the renal pelvis, a small amount of radiographic contrast medium was flushed if needed to assure the ureteric catheter position. Then a Foley urethral catheter (8-10 Fr) was inserted and fixed with the ureteric catheter on the side of the thigh. We performed the procedure in supine position with the patient's side of the procedure at the edge of the operating table without putting any support under the flank, then sterilization of the skin by povidone-iodine $10 \%$ solution, then putting towels on the patient, then opacifying the col- lecting system by inserting the contrast medium through the ureteric catheter, the specific calyx was punctured by using a fluoroscopy $\mathrm{C}$-arm at 0 and 30 degree by using 18 gauge puncture needle [Figure1], after assuring of being in the collecting system an angled tip, 0.035 inch diameter, $180 \mathrm{~cm}$ length, hydrophilic guidewire was inserted via puncture needle and it will be better to go through the ureter to the bladder.

Figure 1. Patient position

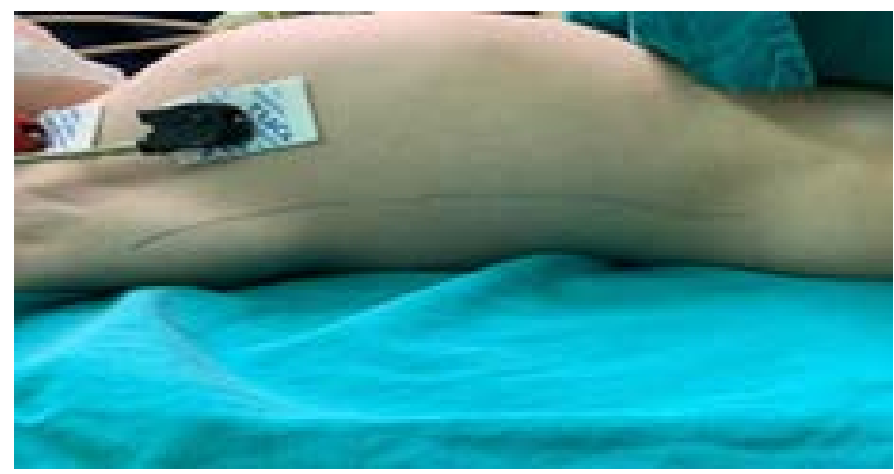

The Teflon dilators $12 \mathrm{Fr}$ then $14 \mathrm{Fr}$ were used to dilate the track. The $14 \mathrm{Fr}$ metal sheath was then passed over the $14 \mathrm{~F}$ dilator, 14 Fr dilator is removed after assuring of the sheath inside the collecting system under fluoroscopy. This metal sheath $14 \mathrm{~F}$ has a sideway for connection with suction system which facilitate retrieval of gravels through the procedure. Stones were fragmented using 12Fr RZ nephroscope and by a holmium: YAG laser (Lisa; Sphinx $30 \mathrm{~W}$, Katlenburg University, Germany) ( $272 \mu$ caliber fiber), and removal of the fragments by using the stone grasper and also by suction through the side way of the metal sheath. At the end of the maneuver in some cases (12 out of 17 patients) we keep the ureteric in place together with insertion of 12ch nephrostomy tube, in the remaining 5 cases we replaced the ureteric catheter by 4.8 ch double J stent [Figure2].

Figure 2. Renal dilation

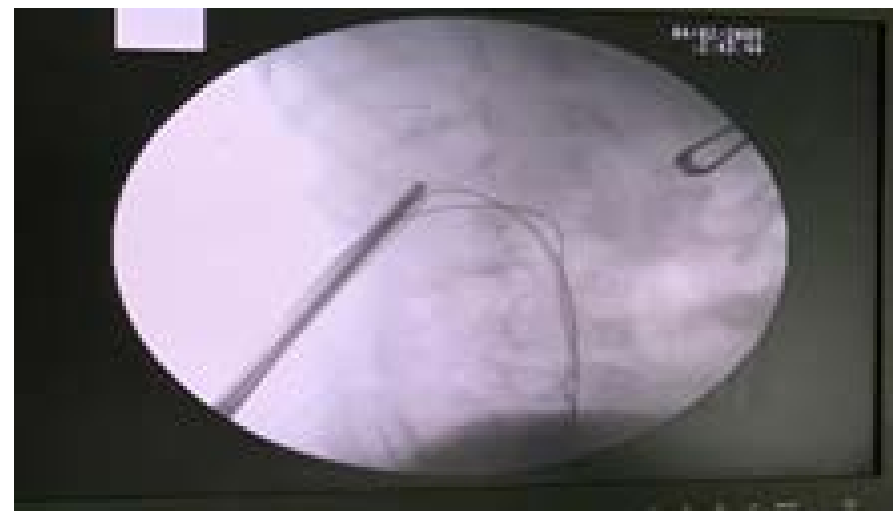

\section{RESULTS}

The data in this study included 17 patients ( 12 male and 5 female) with a renal pelvis or calyceal stone. The Mean of age was $5.6 \pm 6.91$ years. 12 patients $(70.5 \%)$ had right renal stones \& 5 patients $(29.5 \%)$ left ones. Body Mass Index (BMI) was $15.76 \pm 9.34 \mathrm{~kg} / \mathrm{m} 2$. The lower calyx stones were in $14(82.6 \%)$ patients \& $9(55.1 \%)$ patients in pelvis , 
while stones in lower calyx and pelvis were in $2(11.8 \%)$ patients, Mean stone size was $17.43 \pm 5.2 \mathrm{~mm}$, and mean density was $730( \pm 236)$. Mean operative time was $59.71 \pm 19.44 \mathrm{~min}$, while Fluoroscopy times had mean of $8.11 \pm 2.05 \mathrm{~min}$ We also observed that mean preoperative hemoglobin was $12.74 \pm 0.97 \mathrm{~g} / \mathrm{dL}$ (11.5-14.5) g/dL \& mean postoperative hemoglobin was $12.03 \pm 1.0 \mathrm{~g} / \mathrm{dL}$. The hospital stay was $1.41 \pm 0.46$. The stone free rate was $96.2 \%$. Only one case of m PCNL (5.9\%) had significant bleeding and needs one-unit blood to be transfused with no statistical significance. One patient of mini PCNL (5.9\%) had renal pelvic perforation and extravasation which was a small perforation and resolved with Double J stent and conservative measures, nephrostomy tube was inserted in both cases [Table2].

Table 2. Results.
\begin{tabular}{|l|l|}
\hline Operative Time (minutes-Mean \pm SD) & $59.71( \pm 19.44)$ \\
\hline Blood Loss (cc-Mean \pm SD) & $110( \pm 12)$ \\
\hline Aborted Procedure (N/\%) & 0 \\
\hline Conversion (N/\%) & - \\
\hline Stone migration $(N / \%)$ & - \\
\hline Stents ((N/\%) & \\
\hline JJ stent $(N / \%)$ & $1(3.9 \%)$ \\
\hline Ureteric catheter $(N / \%)$ & $16(96.2 \%)$ \\
\hline SFRs $(N / \%)$ & $16(96.2 \%)$ \\
\hline Pelvic $(n / \%)$ & 0 \\
\hline Pelvic \& calyceal & 0 \\
\hline Lower calyceal $(n / \%)$ & $1(3.9 \%)$ \\
\hline
\end{tabular}

\section{DISCUSSION}

KNowadays the technology helps the urologists by providing modern, highly advanced instruments to make treatment modalities safer and more efficient. Both American and European practice guidelines recommended PCNL as primay treatment for large renal stones. ${ }^{15-17}$

Mini PCNL has been proved safe and effective, in 2012, Yan et al. showed that stone free rate in preschool children with single renal stone $<20 \mathrm{~mm}$ treated by mini-PCNL is better than those with more than 2 stones or larger than $20 \mathrm{~mm} .{ }^{18}$ After that Pei lu et al., 2017 showed that using PCNL for treatment of renal stones in children in comparison to RIRS has a higher stone free rate and no difference in operative time and complication rate. ${ }^{19}$ Meanwhile Hyams et al. 2010 recorded $83 \%$ residual stones $<4 \mathrm{~mm}$ in 120 patients treated with RIRS for renal stones $20-30 \mathrm{~mm}$ and the complication rate was $6.7 \% .^{20}$

In 2014 Giusti et al., the stone free rate was $87.7 \%$ in total number of 162 patients with average stone diameter $20.7 \pm 6 \mathrm{~mm}$ treated by RIRS which considered safe and effective. ${ }^{21}$ By comparing the complication rate of mini PCNL and RIRS we will have a lower complication rate in RIRS than in mini-PCNL, however, the morbidity results like hemorrhage, pain and fever of both mini-PCNL and standard PCNL are similar and not common to be faced. ${ }^{22,23}$

Stone size was shown to be an important prognostic factor for the success of mini PCNL, in our study data mean stone size was $17 \pm 43 \mathrm{~mm}$ this was equal to what was published by Fayad et al in $2017,{ }^{24}$ yet this was smaller to what Zengin $\mathrm{K}$ et al, and Koyuncu $\mathrm{H}$ et al worked on. ${ }^{25-26}$ This relatively small stone size may be the reason of high stone free rate we achieved in comparison to other studies SFR, Zengin K et al. ${ }^{25}, 2015$ reported 95.5\% SFR, Koyuncu $\mathrm{H}$ et al, ${ }^{26} 2015$ showed SFR 96.1\%, and
Fayad A, S et al 2017 who worked on an equal mean stone size reported $92.72 \%$ SFR.

The operative time conducted in many studies as Zengin $\mathrm{K}$ et al, ${ }^{25} 2015$ showed mean operative time 63 ( $\mathrm{min}$ ) in mini PCNL, Also Koyuncu $\mathrm{H}$ et $\mathrm{al},{ }^{26} 2015$ study reported mean operative time $62.5 \pm 20.67$ for mini PCNL \& Fayad et al, ${ }^{24} 2017$ showed a relatively longer operating time was 71.66 (10.36) in mini PCNL. In a metaanalysis comparing mini PCNL to RIRS, Hongyang, et al, ${ }^{27,28} 2017$ reported shorter operative time of mini PCNL in relation to RIRS. In our study mean operative time was $59.7 \pm 19.44$ mini PCNL, which was shorter than other stidies(24-26), and may be related to smaller stone size in our study group.

Zengin $\mathrm{K}$ et al. ${ }^{25} 2015$ repoted mean hospital stay of 2.3 day in mini PCNL confirmed by Koyuncu $\mathrm{H}$ et al, ${ }^{26} 2015$ who showed a mean of $2.4 \pm 0.49$ day; these were longer than our mean hospital stay which was reported to be $1.41 \pm 0.46$ day.

We reported minor intraoperative complications in the form of one case of $\mathrm{m}$ PCNL (5.9\%) with significant bleeding for which one unit blood was transfused, one patient of $\mathrm{m}$ PCNL (5.9\%) with renal pelvic perforation and extravasation which was a small perforation and resolved with Double J stent, and nephrostomy tube. In our study complications assessed using the modified Clavien grading System which showed ; Grade 1: one case, grade 2: one case, grade 3A: one case grade $3 \mathrm{~B}$, this was better than what was reported by Zengin $\mathrm{K}$ et $\mathrm{al} .^{25} 2015$ which reported; Grade 1: 5 cases, grade 2: 3 cases, grade $3 \mathrm{~A}$ : one case also grade 3B: one case also 0 in grade $4 \& 5$.

\section{CONCLUSION}

Mini PCNL can be an effective and alternative option for treatment of renal stones $0.5-2 \mathrm{~cm}$ in pediatric age group, Mini PCNL has more operative and postoperative complications but with high SFR. So multicentric studies with larger numbers of patients will be more effective to confirm these results.

\section{CONFLICTS OF INTEREST}

None.

\section{REFERENCES}

1. Kim B.S. Recent Advancement Or Less Invasive Treatment of Percutaneous Nephrolithotomy. Korean J Urol. 205; 56: 614-623. doi: 10.4111/kju.2015.56.9.614

2. Ferakis N, Stavropoulos M. Mini Percutaneous Nephrolithotomy In The Treatment Of Renal And Upper Ureteral Stones: Lessons Learned From A Review of The Literature. Urol Ann. 2015; 7: 141-148. doi: 10.4103/0974-7796.152927

3. Jeong Kuk Lee, Bum Soo Kim, Yoon Kyu Park. Predictive Factors for Bleeding During Percutaneous Nephrolithotomy. Korean J Urol. 2013; 54: 448-53. doi: 10.4111/kju.2013.54.7.448

4. Turk C, Knoll T, Petrik A, Sarica K, Skolarikos A, Straub M, et al. Guidelines on Urolithiasis. Arnheim (NL): European Association of Urology; 2015.

5. Umbreit EC, Childs MA, Patterson DE, Torres VE, LeRoy AJ, Gettman MT. Percutaneous Nephrolithotomy For Large or Multiple Upper Tract Calculi and Autosomal Dominant Polycystic Kidney Disease. J Urol. 2010; 183(1): 183-187. doi: 10.1016/j.juro.2009.08.141 
6. Yuruk E, Binbay M, Sari E, Akman T, Altinyay E, Baykal M, et al. A Prospective, Randomized Trial of Management for Asymptomatic Lower Pole Calculi. J Urol. 2010; 183: 1424-1428. doi: 10.1016/j. juro.2010.05.010

7. Sabins RB, Ganesamoni R, Sarpal R. Miniperc: What Is Its Current Status? Curr Opin Urol. 2012; 22: 129-133. doi: 10.1097/ MOU.0b013e3283502fb4

8. Lee JW, Park J, Lee SB, Son H, Cho SY, Jeong H. Mini Percutanoues Nephrolithotomy vs Retrograde Intrarenal Surgery For Renal Stones Larger Than $10 \mathrm{~mm}$ : Prospective Randomized Controlled Trial; Urology; 2015; 86(5): 873-877. doi: 10.1016/j.urology.2015.08.011

9. Abdel-Razzak OM, Bagley DH. Clinical Experience With Flexible Ureteropyeloscopy. J Urol; 1992 ; 148(6): 1788-1792. doi: 10.1016/s00225347(17)37030-1

10. Zengin K, Tanik S, Karakoyunlu N, Sener NC, Albayrak S, Tuygun C,et al. Retrograde Intrarenal Surgery versus Percutaneous Lithotripsy to Treat Renal Stones 2-3cm in Diameter. Biomed Res Int. 2015; 2015: 914231. doi: 10.1155/2015/914231

11. Bagley DH. Expanding role of Ureteroscopy and Laser Lithotripsy for Treatment Of Proximal Ureteral and Intrarenal Calculi. Current Opinion in Urology. 2002; 12 (4): 277-280. doi: 10.1097/00042307-20020700000003

12. Breda A, Ogunyemi O, Leppert JT, Lam JS, Schulam PG. Flexible Ureteroscopy And Laser Lithotripsy For Single Intrarenal Stones $2 \mathrm{~cm}$ or Greater is This the New Frontier? Journal of Urology. 2008; 179 (3), 981984. doi: 10.1016/j.juro.2007.10.083

13. Azili MN, Ozcan F, Tiryaki T. Retrograde Intrarenal Surgery for The Treatment Of Renal Stones In Children: Factors Influencing Stone Clearance and Complications. J Pediatr Surg. 2014; 49: 1161-1165. doi: 10.1016/j.jpedsurg.2013.12.023

14. Annamaria Salerno, Simona Gerocarni Nappo, Ennio Matarazzo, Mauro De Dominicis, Paolo Caione. Treatment of Pediatric Renal Stones in A Western Country: A Changing Pattern. J Pediatr Surg. 2013; 48: 835-839. doi: 10.1016/j.jpedsurg.2012.09.058

15. Tu"rk C, Knoll T, Petrik A, et al. Guidelines on Urolithiasis. European Urological Association Web site. Available at http://uroweb.org/ wp-content/uploads/EAU-GuidelinesUrolithiasis-2016-1.pdf (Last accessed: March 18, 2017).

16. Shuba De, Riccardo Autorino, Fernando J Kim, et al. Percutaneous Nephrolithotomy versus Retrograde Intrarenal Surgery: A Systematic Review And Meta-Analysis. Eur Urol. 2015; 67: 125-137. doi: 10.1016/j. eururo.2014.07.003

17. Hakan Kilicarslan, Yurdaer Kaynak, Yakup Kordan, Onur Kaygisiz, Burhan Coskun, Kadir Omur Gunseren, et al. Unfavorable Anatomical Factors Influencing The Success of Retrograde Intrarenal Surgery For Lower Pole Renal Calculi. J Urol. 2015; 12: 2065-2068.

18. Xiang Yan, Samih Al-Hayek, Weidong Gan, Wei Zhu, Xiaogong Li,
Hongqian Guo. Minimally Invasive Percutaneous Nephrolithotomy in Preschool Age Children with Kidney Calculi (including stones induced by melamine-contaminated milk powder). Pediatr Surg Int. 2012; 28: 1021-1024. doi: 10.1007/s00383-012-3112-8

19. Pei Lu 1, Rijin Song, Yuzhou Yu, Jie Yang, Kai Qi, Rongzhen Tao, Keliang Chen. Clinical Efficacy of Percutaneous Nephrolithotomy versus Retrograde Intrarenal Surgery For Pediatric Kidney Urolithiasis. Medicine (Baltimore). 2017; 96(43): e8346. doi: 10.1097/ MD.0000000000008346

20. E. S. Hyams, R. Munver, V. G. Bird, J. Uberoi, and O. Shah, Flexible Ureterorenoscopy And Holmium Laser Lithotripsy For The Management of Renal Stone Burdens That Measure 2 To $3 \mathrm{Cm}$ : A Multi-Institutional Experience. J Endourol. 2010; 24(10): 1583-1588. doi: 10.1089/ end.2009.0629

21. Guido Giusti, Silvia Proietti, Lorenzo G Luciani, Roberto Peschechera, Antonella Giannantoni, Gianluigi Taverna, et al. Is Retrograde Intrarenal Surgery For The Treatment Of Renal Stones With Diameters Exceeding 2 Cm Still A Hazard? Can J Urol. 2014; 21(2): 7207-7212.

22. H Soylemez, B Altunoluk, Y Bozkurt, AA Sancaktutar N. Penbegul, M. Atar. "Radiation Exposure-Do Urologists Take " It Seriously in Turkey?”. J Urol . 2012; 187(4): 1301-1305. doi: 10.1016/j.juro.2011.11.110

23. Rajiv Goel, Monish Aron, Pawan K. Kesarwani, P. N. Dogra, A.K. Hemal, et al. Percutaneous Antegrade Removal of Impacted Upper-Ureteral Calculi: Still The Treatment of Choice In Developing Countries. Journal of Endourology. 2005; 19(1): 54-57. doi: 10.1089/end.2005.19.54

24. Fayad AS, Elsheikh MG, Ghoneima W. Tubeless Mini-Percutaneous Nephrolithotomy Versus Retrograde Intrarenal Surgery For Lower Calyceal Stones of $\leqslant 2 \mathrm{Cm}$ : A Prospective Randomised Controlled Study. Arab J Urol. 2017; 151: 36-41. doi: 10.1016/j.aju.2016.10.002

25. Kursad Zengin, Serhat Tanik, Nihat Karakoyunlu, Nevzat Can Sener, Sebahattin Albayrak, Can Tuygun, Hasan Bakirtas, M. Abdurrahim Imamoglu, and Mesut Gurdal Retrograde Intrarenal Surgery versus Percutaneous Lithotripsy to Treat Renal Stones $2-3 \mathrm{~cm}$ in Diameter, BioMed Research International, Volume 2015, Article ID 914231.

26. Koyuncu H, Yencilek F, Kalkan M, Bastug Y, Yencilek E, Ozdemir AO. Intrarenal Surgery vs Percutaneous Nephrolithotomy in the Management of Lower Pole Stones Greater than $2 \mathrm{~cm}$. 2015; 41: 2. doi: 10.1590/S1677-5538.IBJU.2015.02.09

27. Fayad AS, Elsheikh MG, Ghoneima W. Tubeless Mini-Percutaneous Nephrolithotomy Versus Retrograde Intrarenal Surgery For Lower Calyceal Stones of $\leqslant 2 \mathrm{Cm}$ : A Prospective Randomised Controlled Study. Arab Journal of Urology. 2017; 15(1): 36-41. doi: 10.1016/j. aju.2016.10.002

28. Hongyang Jiang, Zhe Yu, Liping Chen, et al. Minimally Invasive Percutaneous Nephrolithotomy versus Retrograde Intrarenal Surgery for Upper Urinary Stones: A Systematic Review and Meta-Analysis. Biomed Res Int. 2017; 2017: 2035851. doi: 10.1155/2017/2035851 